\title{
Inhibition of Aluminium Corrosion in 1.0 M HCl by Caffeine: Experimental and DFT Studies
}

\author{
R. H. B. Beda, P. M. Niamien, E. B. Avo Bilé, and A. Trokourey \\ Laboratoire de Chimie Physique, Université Félix Houphouët Boigny, 22BP 582, Abidjan 22, Côte d'Ivoire \\ Correspondence should be addressed to P. M. Niamien; niamienfr@yahoo.fr
}

Received 19 October 2017; Revised 24 November 2017; Accepted 28 November 2017; Published 24 December 2017

Academic Editor: Franck Rabilloud

Copyright (c) 2017 R. H. B. Beda et al. This is an open access article distributed under the Creative Commons Attribution License, which permits unrestricted use, distribution, and reproduction in any medium, provided the original work is properly cited.

\begin{abstract}
Aluminium corrosion inhibition in $1.0 \mathrm{M}$ hydrochloric acid solution by caffeine has been studied using mass loss technique and quantum chemical calculations based on DFT. The inhibition efficiency was found to increase with increasing concentration of caffeine but decreases with a rise in temperature. The molecule shows the highest inhibition efficiency of $74 \%$ at $10^{-2} \mathrm{M}$ for $T=303 \mathrm{~K}$. The experimental data were used to fit isotherms including Langmuir, Temkin, Freundlich, and El-Awady. The best fits were obtained with the Langmuir model and the kinetic-thermodynamic adsorption model of El-Awady. However, it was found that the adsorption parameters suit well with the isotherm of El-Awady which was chosen as the appropriate isotherm. To distinguish between physisorption and chemisorption, the Dubinin-Radushkevich adsorption model was used. The thermodynamic parameters governing the adsorption of caffeine onto aluminium and that of the metal dissolution were calculated and discussed. DFT study gave further insight into the mechanism of the inhibiting action of caffeine.
\end{abstract}

\section{Introduction}

Aluminium and its alloys $[1,2]$ are used in many applications in industries (aerospace, household industries, electronic devices, food industry, etc.) due to their low price, high electrical capacity, and their high energy density. Though aluminium has the ability to form a stable thin oxide film that protects it from the corrosion phenomenon, it undergoes corrosion [3-5] when being in contact with aggressive media such as hydrochloric acid.

Corrosion control can be achieved by many methods; however, the use of corrosion inhibitors is actually the most practical method used in industries and academic studies. A survey of the literature reveals [6-8] that most of the wellknown ecofriendly corrosion inhibitors are organic compounds containing nitrogen, oxygen, sulphur, and/or $\pi$ bonds in their molecular structure. Several heterocyclic N, S, or O containing organic compounds [9-12] have been used to protect aluminium from hydrochloric acid corrosion.

Generally, localized corrosion [4] can be avoided by the action of adsorption inhibitors, which prevent the adsorption of aggressive anions or by the formation of a more resistant oxide film on the metal surface.
The adsorption of a given organic compound onto a metal surface is influenced by its chemical structure. Therefore, the use of quantum chemical calculations will lead to structural parameters of the molecule. Recently, density functional theory (DFT) has emerged as a reliable and inexpensive method [13] for predicting the properties of chemical systems. Several papers [14-16] have documented the use of DFT to get insight into the corrosion inhibition mechanism by organic molecules.

The aim of this paper is to study the behaviour of caffeine against the hydrochloric acid corrosion of aluminium, using mass loss method and density functional theory calculations.

\section{Material and Methods}

\subsection{Material}

2.1.1. Aluminium Specimens. The aluminium specimens were in the form of rod measuring $10 \mathrm{~mm}$ in length and $2 \mathrm{~mm}$ in diameter; they were cut in commercial aluminium of purity 99.5\%. 
2.1.2. Chemicals. All chemicals were of analytical grade and were used without further purification:

(i) $\mathrm{HCl}$ from Merck with purity: $37 \%$.

(ii) Caffeine $\left(\mathrm{C}_{8} \mathrm{H}_{10} \mathrm{~N}_{4} \mathrm{O}_{2}\right)$ was acquired from Sigma Aldrich chemicals and solutions of concentrations range from $0.1 \mathrm{mM}$ to $10 \mathrm{mM}$ were prepared.

(iii) Acetone from Sigma Aldrich with purity: 99.5\%.

\subsection{Methods}

2.2.1. Mass Loss Method. The mass loss method [17, 18] is probably the most widely used method of inhibition assessment. The simplicity and reliability of the measurement offered by mass loss method [19] make the technique form the baseline method in many corrosion monitoring programs.

Prior to the immersion of the specimens in the test solution $(50 \mathrm{~mL})$, their surface was abraded with different grade of emery papers (120-180-240-600-1200) to mirror finish, rinsed with acetone, washed with bidistilled water, and finally dried in a desiccator. The mass loss experiments were performed under total immersion in the acidic solution of $1.0 \mathrm{M}$ (with or without caffeine), opened to the air. The temperature was controlled by a water thermostat. After one-hour immersion, the specimens were retrieved from the solution, washed with a bristle brush under running water in order to remove the corrosion product, dried in a desiccator, and weighed accurately. The study was performed in the temperature range of $303 \mathrm{~K}$ to $323 \mathrm{~K}$ and the concentration range of $0.1 \mathrm{mM}$ to $10 \mathrm{mM}$. The tests were repeated three times for each solution and at the same temperature. The mean value was then recorded.

The corrosion rate $(W)$ in $\mathrm{g} \cdot \mathrm{cm}^{-2} \cdot \mathrm{h}^{-1}$ was calculated using the following equation:

$$
W=\frac{m_{1}-m_{2}}{S t},
$$

where $m_{1}$ is the mass of the sample before immersion in the test solution, $m_{2}$ is the mass after $1 \mathrm{~h}$ immersion in the test solution, $S$ is the total surface of the sample, and $t$ is the immersion time. The inhibition efficiency IE (\%) was calculated according to the equation below:

$$
\operatorname{IE}(\%)=\frac{W_{0}-W}{W_{0}} \times 100,
$$

where $W_{0}$ is the corrosion rate in the absence of the tested molecule and $W$ is the corrosion rate in its presence.

2.2.2. Quantum Chemistry Calculations. The calculations were performed using the hybrid functional B3LYP, a version of DFT functional that uses Becke's three parameter functional (B3) with a mixture of HF and DFT exchange terms associated with the gradient corrected correlation functional of Lee et al. [20]. The full geometry optimization was carried out at B3LYP/6-31G (d) level of theory, using Gaussian 03W [21].

The calculations were carried out in gas phase to show the relationship between the molecular descriptors of caffeine

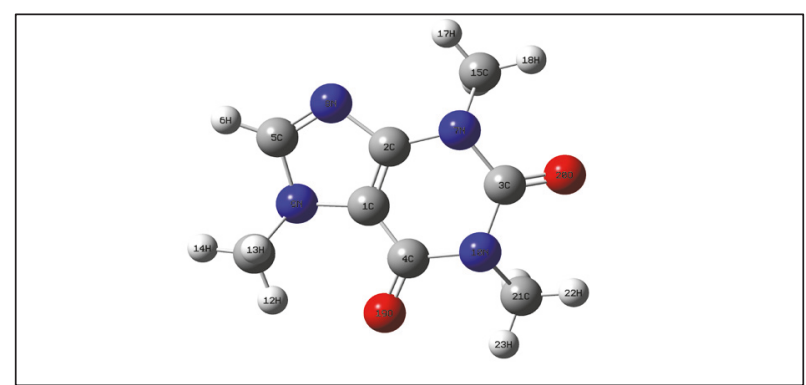

FIGURE 1: Optimized structure of caffeine by B3LYP/6-31G (d).

and its inhibition efficiency. The optimized minimum energy geometrical configuration of caffeine is given in Figure 1.

DFT [22] has been found to be successful in providing theoretical insights into the chemical reactivity and selectivity, using chemical concepts such as electronegativity $(\chi)$, hardness $(\eta)$, softness $(S)$, electrophilicity index $(\omega)$, and local reactivity descriptors including Fukui functions $f(r)$ and the local softness $s(r)$.

Density functional theory (DFT) states that changes in electronic energy $d E[\rho(r)]$ are related to changes in the number of electrons $N$ and changes in the external potential $v(r)$ felt by the electron distribution (which refers to the nuclear position in chemical systems):

$$
d E[\rho(r)]=\mu_{P} d N+\int \rho(r) d v(r) d r .
$$

According to Parr et al. [23], the chemical potential $\mu_{P}$ is linked with the first derivative of the energy with respect to the number of electrons and therefore with the negative of the electronegativity by the following equation:

$$
\mu_{P}=\left(\frac{\partial E}{\partial N}\right)_{v(r)}=-\chi
$$

where $\mu_{P}$ is the electronic chemical potential, $E$ is the total energy, $N$ is the number of electrons, and $v(r)$ is the external potential of the system.

The second partial derivative of the energy with respect to the number of electrons has been defined as hardness $(\eta)$ :

$$
\eta=\left(\frac{\partial^{2} E}{\partial N^{2}}\right)_{v(r)}=\left(\frac{\partial \mu_{P}}{\partial N}\right)_{v(r)} .
$$

This quantity [24] measures both the stability and the reactivity of the molecule.

According to Koopmans's theorem [25], the ionization potential $(I)$ and the electron affinity $(A)$ of the inhibitors are calculated using the following equations:

$$
\begin{aligned}
I & =-E_{\text {HOMO }}, \\
A & =-E_{\text {LUMO }} .
\end{aligned}
$$

The electronegativity $(\chi)[24]$ which measures the power of an atom or group of atoms to attract electrons towards itself can then be written as

$$
\chi=\frac{I+A}{2} .
$$


The chemical hardness $(\eta)$ [24] which expresses the resistance of an atom to charge transfer is estimated using the equation below:

$$
\eta=\frac{I-A}{2}
$$

The inverse of the hardness, known as softness (S) [24], measures the capacity of an atom or group of atoms to receive electrons; it is estimated by

$$
S=\frac{1}{\eta}=\frac{2}{I-A} .
$$

The fraction of electrons transferred from the inhibitor molecule to the metallic surface was calculated using the following equation [26]:

$$
\Delta N=\frac{\chi_{M}-\chi_{\mathrm{inh}}}{2\left(\eta_{M}+\eta_{\mathrm{inh}}\right)}=\frac{\phi_{M}-\chi_{\mathrm{inh}}}{2 \eta_{\mathrm{inh}}},
$$

where $\left(\chi_{M}, \eta_{M}\right)$ and $\left(\chi_{\text {inh }}, \eta_{\text {inh }}\right)$ are, respectively, the electronegativity and hardness of the metal and the inhibitor when $\phi_{M}$ is the work function. In our study, the theoretical values of electronegativity $\phi_{\mathrm{Al}}=4.28 \mathrm{eV}$ [27] and hardness $\eta_{\mathrm{Al}}=0[26]$ have been used for aluminium.

The global electrophilicity index, introduced by Parr et al. [28], is given by the equation below:

$$
\omega=\frac{\mu_{P}^{2}}{2 \eta} .
$$

This index [28] measures the propensity of chemical species to accept electrons. A good nucleophile is characterized by a low value of $\omega$ whereas a good electrophile is characterized by a high value of $\omega$.

Fukui function [29] is one of the widely used local density functional descriptors to model chemical reactivity and site selectivity; it is defined as the derivative of the electron density $\rho(r)$ with respect to $N$, the total number of electrons in the system, at constant external potential $v(r)$ acting on an electron due to all the nuclei in the system:

$$
f(r)=\left(\frac{\partial \mu_{P}}{\partial v(r)}\right)_{N}=\left(\frac{\partial \rho(r)}{\partial N}\right)_{v(r)} .
$$

The condensed Fukui functions are calculated using Yang and Mortier procedure [30] based on a finite difference method:

$$
\begin{aligned}
& f_{k}^{+}=q_{k}(N+1)-q_{k}(N), \\
& f_{k}^{-}=q_{k}(N)-q_{k}(N-1),
\end{aligned}
$$

where $q_{k}$ is the electronic population of atom $k$ in the molecule. The functions $f_{k}^{+}$and $f_{k}^{-}$are, respectively, related to nucleophilic and electrophilic attacks.

The local softness [31] is defined as

$$
s_{k}^{\alpha}=f_{k}^{\alpha} S \quad(\alpha=+ \text { ou }-) .
$$

The maximum values of relative nucleophilicity index $\left(s_{k}^{+} / s_{k}^{-}\right)$ and relative electrophilicity index $\left(s_{k}^{-} / s_{k}^{+}\right)$are used to define, respectively, the probable sites of nucleophilic and electrophilic attacks.

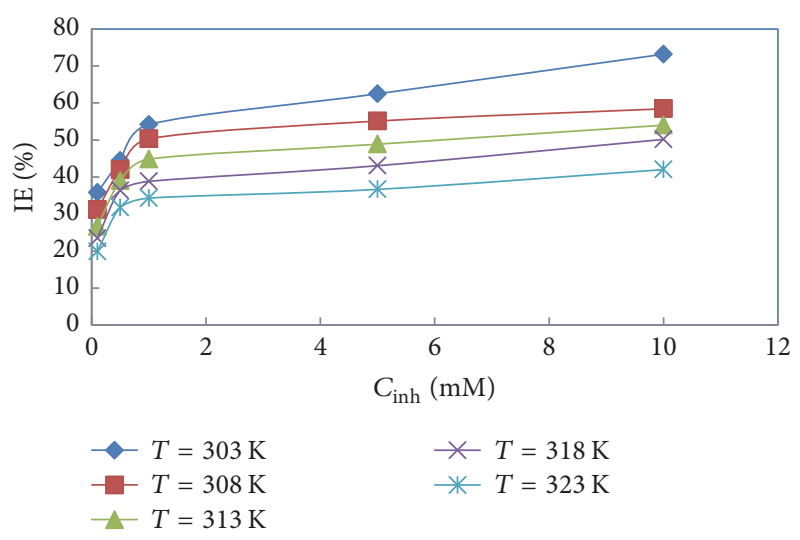

FIGURE 2: Inhibition efficiency of caffeine against aluminium corrosion in $1.0 \mathrm{M} \mathrm{HCl}$ versus concentration for different temperatures.

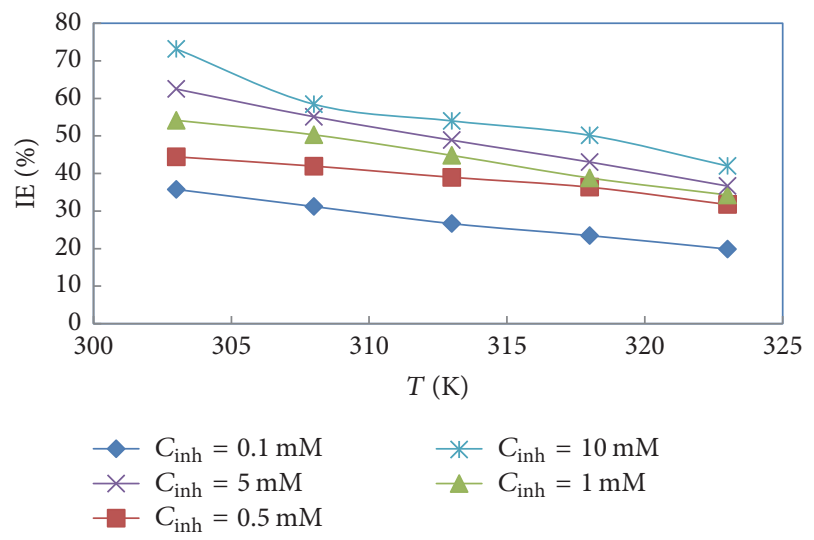

FIGURE 3: Inhibition efficiency of caffeine against aluminium corrosion in $1.0 \mathrm{M} \mathrm{HCl}$ versus temperature for different concentrations.

\section{Results and Discussion}

3.1. Mass Loss Technique. Figures 2 and 3 illustrate the evolution of the inhibition efficiency of caffeine against aluminium corrosion in $1.0 \mathrm{M} \mathrm{HCl}$ after 1-hour immersion, respectively, for different concentrations and temperatures.

It is clear from these figures that the inhibition efficiency increases with increasing concentration of caffeine but decreases with a rise in temperature. The increase in inhibition efficiency with concentration may be due to the adsorption of caffeine onto the aluminium surface through nonbonding electron pairs of nitrogen and oxygen atoms as well as the $\pi$-electrons of the aromatic rings. The surface of the metal is therefore covered by a protective layer film, which separates it from its environment. Similar observation $[32,33]$ has been reported in the literature.

Though the effect of temperature on the inhibited acidmetal reaction is complex [34] due to many changes on the metal surface (rapid etching, desorption of molecules, etc.), the decrease in inhibition efficiency with a rise in temperature may probably due to increased rate of desorption of the inhibitor. 


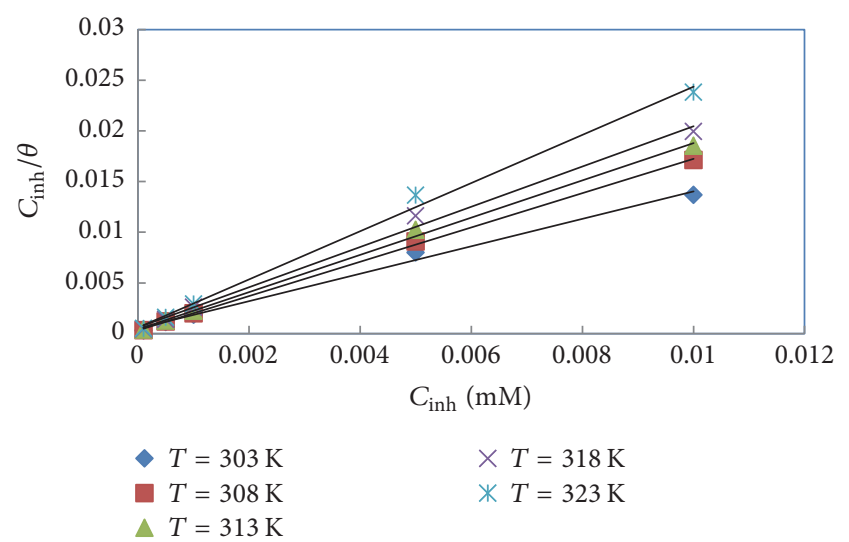

FIGURE 4: Langmuir adsorption plots for aluminium in presence of caffeine.

3.1.1. Adsorption Isotherm. It is admitted [35] that the first step in corrosion inhibition of metals by organic compounds is their adsorption onto the metal surface. This phenomenon is regarded [35] as a quasi-substitution process between organic compounds in the aqueous phase $\mathrm{Org}_{(\mathrm{sol})}$ and water molecules at the metal surface $\mathrm{H}_{2} \mathrm{O}_{(\mathrm{ads})}$ :

$$
\mathrm{Org}_{(\mathrm{sol})}+x \mathrm{H}_{2} \mathrm{O}_{(\mathrm{ads})} \rightleftarrows \mathrm{Org}_{(\mathrm{ads})}+x \mathrm{H}_{2} \mathrm{O}_{(\mathrm{sol})}
$$

where $x$ is the size ratio, the number of water molecules replaced by one inhibitor. Information on the interaction between the inhibitor and the metal surface can be obtained using adsorption isotherms. The isotherms are in general form:

$$
K_{\mathrm{ads}} C_{\mathrm{inh}}=f(\theta, x) \exp (-\alpha \theta),
$$

where $f(\theta, x)$ is the configurational factor, subject to the physical model and assumptions involved in the derivation of the isotherm, $\alpha$ is a molecular interaction parameter, $C_{\text {inh }}$ is the inhibitor concentration, and $K_{\mathrm{ads}}$ is the adsorption constant.

Attempts were made to fit experimental data $\left(\theta\right.$ and $\left.C_{\text {inh }}\right)$ to some classical isotherms including Langmuir, El-Awady, Freundlich, and Frumkin. By far the best fits were obtained with the isotherm of Langmuir $\left(R^{2}>0.99\right)$ and that of ElAwady $\left(R^{2}>0.98\right)$. In Langmuir isotherm, $\theta$ and $C_{\text {inh }}$ are related by the following equation:

$$
\frac{C_{\mathrm{inh}}}{\theta}=\frac{1}{K_{\mathrm{ads}}}+C_{\mathrm{inh}}
$$

Figure 4 depicts the plots of $C_{\text {inh }} / \theta$ versus $C_{\text {inh }}$.

The slopes of the straight lines obtained are higher than unity for all the temperatures. The considerable deviation from unity observed may be due to the interactions among the adsorbed species on the metal surface. It is therefore pertinent to say that the adsorption can be more appropriately represented by a modified Langmuir equation: the isotherm of Villamil et al. [36] or that of El-Awady. The parameters of these isotherms are collected in Table 1.

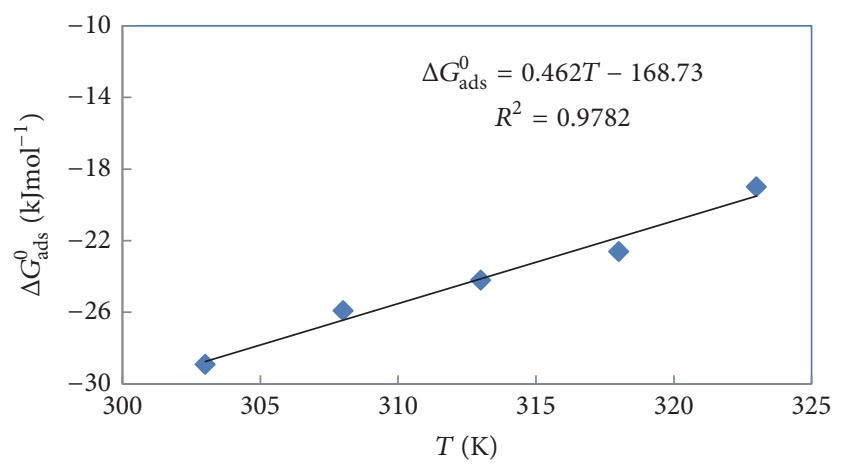

FIgURE 5: $\Delta G_{\text {ads }}^{0}$ versus temperature for aluminium in presence of caffeine.

The adsorption constants $K_{\text {ads }}$ have been calculated using the equations in Table 1 . The changes in standard adsorption free enthalpy have been calculated using the following equation:

$$
\Delta G_{\mathrm{ads}}^{0}=-R T \ln \left(55.5 \times K_{\mathrm{ads}}\right),
$$

where $R$ is the gas constant, $T$ is the absolute temperature, and 55.5 is the concentration of water (in $\mathrm{mol} \mathrm{L}^{-1}$ ) in the solution.

In Villamil equation " $n$ " is a constant introduced to consider all the factors, not taken into account in the derivation of Langmuir isotherm.

The constant $y$ in the isotherm of El-Awady is the number of active sites on the material surface; $1 / y$ less than one implies a multilayer adsorption, while $1 / y$ greater than one suggests that a given inhibitor molecule occupies more than one active site.

It is clear from Table 1 that only the kinetic-thermodynamic adsorption isotherm of El-Awady supports well the trend of decrease in inhibition efficiency (decrease of the adsorption constant with rise of temperature); therefore the appropriate isotherm is that of El-Awady.

In order to determine change in standard adsorption enthalpy $\Delta H_{\text {ads }}^{0}$ and change in standard adsorption entropy $\Delta S_{\text {ads }}^{0}$, we used the basic equation:

$$
\Delta G_{\mathrm{ads}}^{0}=\Delta H_{\mathrm{ads}}^{0}-T \Delta S_{\mathrm{ads}}^{0} .
$$

Plotting $\Delta G_{\text {ads }}^{0}$ versus temperature gives the two adsorption parameters (Figure 5). The negative values of $\Delta G_{\text {ads }}^{0}$ suggest that the adsorption of caffeine onto aluminium is spontaneous. These values range from $-28.9 \mathrm{kJmol}^{-1}$ to $-19 \mathrm{kJmol}^{-1}$, indicating [37] both physisorption and chemisorption processes.

Change in standard adsorption enthalpy $\left(\Delta H_{\mathrm{ads}}^{0}=\right.$ $-168 \mathrm{kJmol}^{-1}$ ) is negative, showing an exothermic adsorption process, and its absolute value is higher than $100 \mathrm{kJmol}^{-1}$, which is according to the literature [38] not a typical chemisorption when referring to the values of $\Delta G_{\mathrm{ads}}^{0}$. It may be indicative of both physisorption and chemisorption processes.

Change in standard adsorption entropy $\left(\Delta S_{\text {ads }}^{0}=\right.$ $-462 \mathrm{Jmol}^{-1} \mathrm{~K}^{-1}$ ) is negative; it may be explained by desorption of the inhibitor species when the temperature increases. 
TABLE 1: Parameters of the modified Langmuir adsorption isotherms.

\begin{tabular}{|c|c|c|c|c|c|c|c|}
\hline Isotherm & Equation & $T(\mathrm{~K})$ & $R^{2}$ & Slope & Intercept & $\begin{array}{c}K_{\text {ads }} \\
\left(\times 10^{3} \mathrm{M}\right) \\
\end{array}$ & $\begin{array}{c}\Delta G_{\mathrm{ads}}^{0} \\
\left(\mathrm{kJmol} \mathrm{mm}^{-1}\right)\end{array}$ \\
\hline \multirow{5}{*}{ Villamil et al. } & \multirow{5}{*}{$\frac{C_{\mathrm{inh}}}{\theta}=\frac{n}{K_{\mathrm{ads}}}+n C_{\mathrm{inh}}$} & 303 & 0.994 & 1.3542 & 0.0007 & 2.768 & -30.1 \\
\hline & & 308 & 0.999 & 1.6943 & 0.0005 & 5.648 & -32.4 \\
\hline & & 313 & 0.998 & 1.8394 & 0.0007 & 4.598 & -32.3 \\
\hline & & 318 & 0.994 & 1.9882 & 0.0012 & 3.314 & -32.0 \\
\hline & & 323 & 0.995 & 2.3771 & 0.0014 & 3.962 & -33.0 \\
\hline \multirow{5}{*}{ El-Awady } & \multirow{5}{*}{$\begin{array}{c}\log \left(\frac{\theta}{1-\theta}\right)=\log K^{\prime}+y \log C_{\mathrm{inh}} \\
K_{\mathrm{ads}}=K^{\prime 1 / y}\end{array}$} & 303 & 0.999 & 0.3421 & 1.1085 & 1.738 & -28.9 \\
\hline & & 308 & 0.996 & 0.2442 & 0.6466 & 0.444 & -25.9 \\
\hline & & 313 & 0.978 & 0.2413 & 0.5539 & 0.197 & -24.2 \\
\hline & & 318 & 0.968 & 0.2435 & 0.4809 & 0.094 & -22.6 \\
\hline & & 323 & 0.992 & 0.2226 & 0.2950 & 0.021 & -19.0 \\
\hline
\end{tabular}

TABle 2: Parameters of the Dubinin-Radushkevich model.

\begin{tabular}{lcccc}
\hline$T(\mathrm{~K})$ & $R^{2}$ & $a\left(\mathrm{~kJ}^{-2} \mathrm{~mol}^{2}\right)$ & $\theta_{\max }$ & $\left.E_{m}(\mathrm{~kJ} \mathrm{~mol})^{-1}\right)$ \\
\hline 303 & 0.991 & 0.0121 & 0.696 & 6.4 \\
308 & 0.995 & 0.0081 & 0.582 & 7.9 \\
313 & 0.984 & 0.0063 & 0.517 & 8.9 \\
318 & 0.965 & 0.0063 & 0.466 & 8.9 \\
323 & 0.974 & 0.0061 & 0.401 & 9.0 \\
\hline
\end{tabular}

Moreover, according to the thermodynamic principles, since the adsorption is an exothermic process, it may be accompanied by a decrease in entropy.

In order to distinguish between physisorption and chemisorption, the isotherm of Dubinin-Radushkevich has been used. This isotherm is characterized [39] by the equation below:

$$
\ln \theta=\ln \theta_{\max }-a \delta^{2},
$$

where $\theta_{\max }$ is the maximum surface coverage and $\delta$ is the Polanyi potential which is given by

$$
\delta=R T \ln \left(1+\frac{1}{C_{\mathrm{inh}}}\right) .
$$

In this equation, $R$ is the perfect gas constant, $T$ is the absolute temperature, and $C_{\text {inh }}$ is the concentration of the inhibitor expressed in $\mathrm{g} \mathrm{L}^{-1}$. Figure 6 gives the plots of $\ln \theta$ versus $\delta^{2}$. The parameters of this model are in Table 2.

The value of the parameter $a$ in (20) leads to the mean adsorption energy $E_{m}$ for the related temperature. This energy is the transfer energy of $1 \mathrm{~mol}$ of adsorbate from infinity (bulk solution) to the surface of the adsorbent. $E_{m}$ is defined as

$$
E_{m}=\frac{1}{\sqrt{2 a}}
$$

In order to determine the range of temperatures for physisorption and chemisorption, we plot $E_{m}$ versus temperature (Figure 7).

According to the literature [39] the magnitude of $E_{m}$ gives information about the adsorption: $E_{m}$ values less than

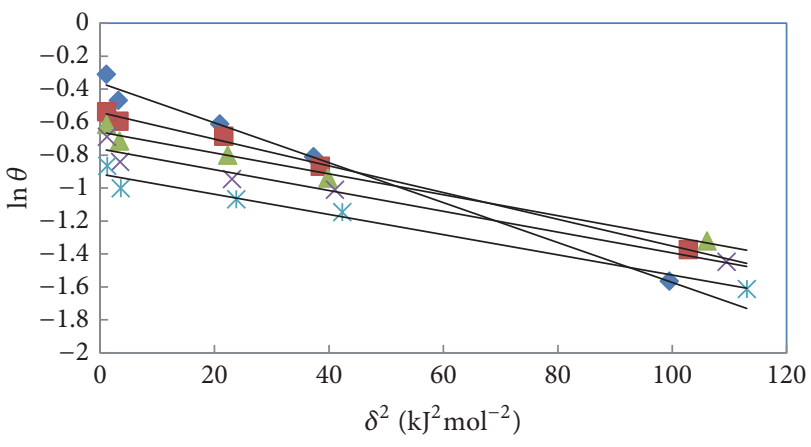

FIgURE 6: Dubinin-Radushkevich isotherm in presence of caffeine.

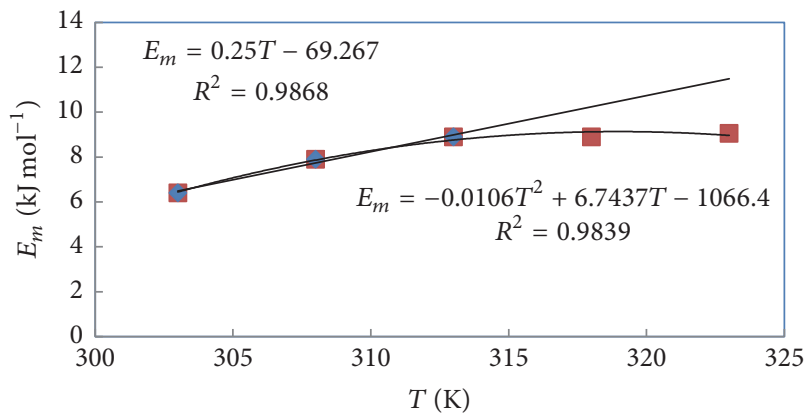

FIGURE 7: Adsorption energy versus temperature for caffeine onto aluminium.

$8 \mathrm{~kJ} \mathrm{~mol}^{-1}$ indicate physical adsorption, while that higher than $8 \mathrm{~kJ} \mathrm{~mol}^{-1}$ suggest chemisorption. Using the equation of the straight line in Figure 7, we derived the domains where 
TABLE 3: Dissolution parameters of the aluminium in $1.0 \mathrm{M} \mathrm{HCl}$.

\begin{tabular}{lccc}
\hline$C_{\text {inh }}(\mathrm{mM})$ & $E_{a}\left(\mathrm{~kJ} \mathrm{~mol}^{-1}\right)$ & $\Delta H_{a}^{*}\left(\mathrm{~kJ} \mathrm{~mol}^{-1}\right)$ & $\Delta S_{a}^{*}\left(\mathrm{~J} \mathrm{~mol}^{-1} \mathrm{~K}^{-1}\right)$ \\
\hline 0 & 77.9 & 75.4 & -34.3 \\
0.10 & 78.8 & 76.3 & -31.5 \\
0.5 & 90.6 & 88.1 & 2.2 \\
1 & 97.0 & 94.5 & 21.9 \\
5 & 100.1 & 97.7 & 31.2 \\
10 & 104.9 & 102.4 & 45.0 \\
\hline
\end{tabular}

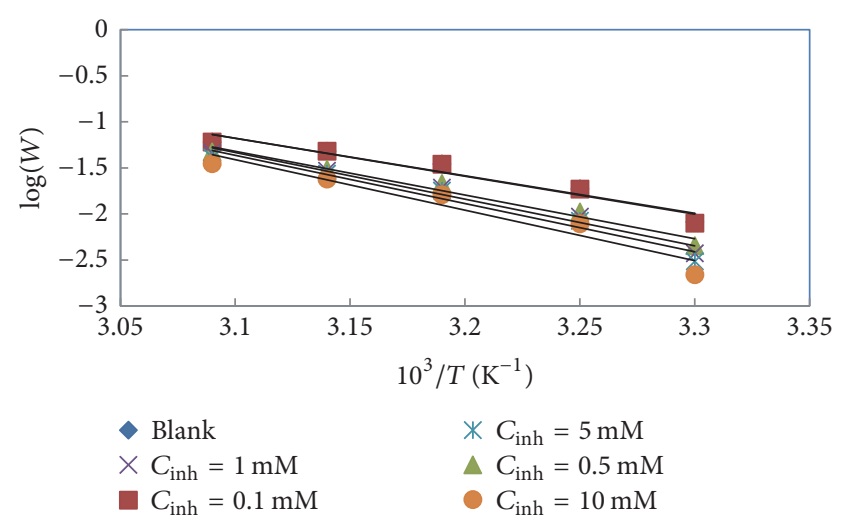

FIGURE 8: Arrhenius plots for aluminium in $1.0 \mathrm{M} \mathrm{HCl}$ at different concentrations of caffeine.

each type of adsorption is predominant $((T<309.1 \mathrm{~K}$ for physisorption) and ( $T>309.1 \mathrm{~K}$ for chemisorption)). The decrease in $\theta_{\max }$ values confirms that the adsorption decreases with increasing temperatures.

3.1.2. Effect of Temperature. To determine the activation parameters of the corrosion process, the Arrhenius and the transition state equations were used:

$$
\begin{aligned}
\log W & =\log A-\frac{E_{a}}{2,303 R T}, \\
\log \left(\frac{W}{T}\right) & =\left[\log \left(\frac{R}{\aleph h}\right)+\frac{\Delta S_{a}^{*}}{2,303 R}\right]-\frac{\Delta H_{a}^{*}}{2.303 R T},
\end{aligned}
$$

where $E_{a}$ is the apparent activation energy, $R$ is the perfect gas constant, $A$ is the frequency factor, $h$ is Planck's constant, $\aleph$ is the Avogadro number, $\Delta H_{a}^{*}$ is the change in activation enthalpy, and $\Delta S_{a}^{*}$ is the change in activation entropy.

Values of apparent activation energy of corrosion $\left(E_{a}\right)$ for aluminium in $\mathrm{HCl}$ in the absence and presence of various concentrations of caffeine were determined from the slope of $\log W$ versus $1 / T$ plots (Figure 8 ).

The values of change in enthalpy $\left(\Delta H_{a}^{*}\right)$ and change in entropy $\left(\Delta S_{a}^{*}\right)$ were obtained, respectively, from the slopes and intercepts of the plots of $\log (W / T)$ versus $1 / T$ (Figure 9). All these parameters are collected in Table 3.

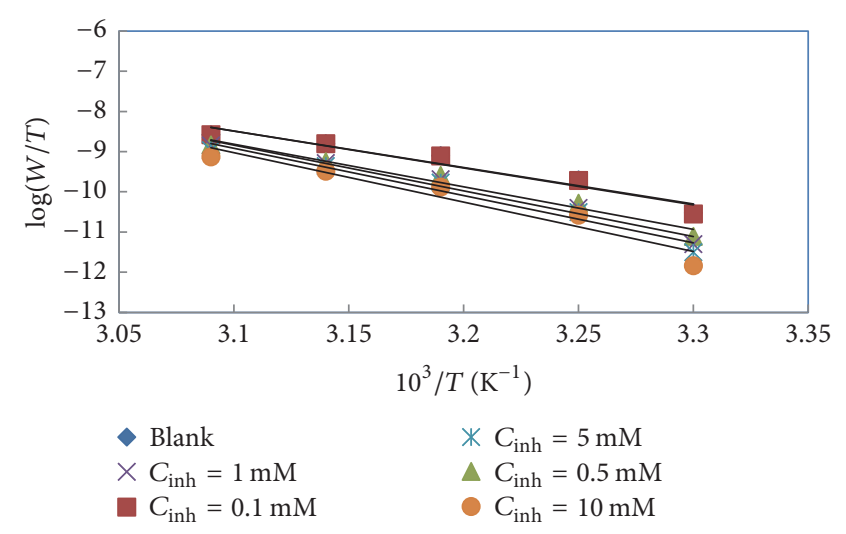

FIgURE 9: Transition state plots of aluminium in $1.0 \mathrm{M} \mathrm{HCl}$ at different concentrations of caffeine.

From Table 3, one can notice that $E_{a}$ and $\Delta H_{a}^{*}$ vary in the same way. This result permitted verifying the known thermodynamic relation between the two activation parameters:

$$
\Delta H_{a}^{*}=E_{a}-R T .
$$

The activation energies $E_{a}$ are all positive and those of the inhibited solutions are higher than those of the blank (uninhibited solution), suggesting [40] a physisorption process or a mix process. The positive sign of change in activation enthalpy $\Delta H_{a}^{*}$ reflects the endothermic nature of the aluminium dissolution process. The values of change in activation enthalpy increase with increasing concentration of caffeine, showing that the dissolution of the aluminium becomes more and more difficult and slow.

The change in activation entropy $\Delta S_{a}^{*}$ increases with increasing concentration in caffeine, indicating that an increase in disordering takes place on going from the reactants to the activated complex. This situation could explain the decrease in the rate of surface coverage.

3.2. Quantum Chemical Approach. The quantum chemical parameters of caffeine obtained from the calculations include the energy of the highest occupied molecular orbital $\left(E_{\mathrm{HOMO}}\right)$, the energy of the lowest unoccupied molecular orbital $\left(E_{\mathrm{LUMO}}\right)$, the energy gap $\left(\Delta E=E_{\mathrm{LUMO}}-E_{\mathrm{HOMO}}\right)$, the dipole moment, $\mu$ and the total energy (TE). Based on frontier molecular orbital (FMO), the reactivity parameters such as the ionization energy $(I)$, the electronic affinity $(A)$, the global electronegativity $(\chi)$, the global hardness $(\eta)$, the global softness $(S)$, the fraction of electrons transferred $(\Delta N)$, and 
TABLE 4: Molecular properties of caffeine calculated with B3LYP/6$31 G(d)$.

\begin{tabular}{lc}
\hline Parameter & Value \\
\hline$E_{\text {HOMO }}(\mathrm{eV})$ & -5.959 \\
$E_{\mathrm{LUMO}}(\mathrm{eV})$ & -0.819 \\
$\Delta E(\mathrm{eV})$ & 5.140 \\
$I(\mathrm{eV})$ & 5.959 \\
$A(\mathrm{eV})$ & 0.819 \\
$\chi(\mathrm{eV})$ & 3.389 \\
$\eta(\mathrm{eV})$ & 2.570 \\
$\left.S(\mathrm{eV})^{-1}\right)$ & 0.389 \\
$\mu(\mathrm{Debye})$ & 3.835 \\
$\Delta N$ & 0.173 \\
$\omega(\mathrm{eV})$ & 2.234 \\
$\mathrm{TE}(\mathrm{a} . \mathrm{u})$ & -680.4 \\
\hline
\end{tabular}

the electrophilicity index $(\omega)$ were also calculated. All these parameters are listed in Table 4.

The HOMO energy [41] is directly related to the ionization energy and characterizes the tendency of the molecule to donate electrons to the unoccupied orbitals of metals. Organic molecules [42] with less negative HOMO values are expected to have high donation ability and therefore high inhibition efficiency. The LUMO energy is another significant reactivity parameter which is related to the electron affinity and characterizes the capacity of a molecule to gain electron from a metal. The lower the value of the LUMO energy, the stronger the electron accepting ability of the molecule [43]. In our case, caffeine has a high value of HOMO energy $\left(E_{\mathrm{HOMO}}=-5.959 \mathrm{eV}\right)$ and a low value of $E_{\mathrm{LUMO}}\left(E_{\mathrm{LUMO}}=\right.$ $-0.819 \mathrm{eV}$ ) when compared with values in the literature [15, 44]. So, the incomplete filled $3 p$ of aluminium (electronic structure: $\left.1 s^{2} 2 s^{2} 2 p^{6} 3 s^{2} 3 p^{1}\right)$ could bond with the HOMO of caffeine while the filled $3 \mathrm{~s}$ orbital could interact with its LUMO.

The energy gap ( $\left.\Delta E=E_{\mathrm{LUMO}}-E_{\mathrm{HOMO}}\right)$ is an important parameter related to the reactivity of an inhibitor towards the adsorption onto a metallic surface. Lower values of $\Delta E$ [45] suggest better adsorption and then better inhibition efficiency. In our case $(\Delta E=5.140 \mathrm{eV})$ can be considered [46-48] as a low value when compared with other values in the literature.

The dipole moment $\mu$ is widely used as a reactivity parameter; it results from the nonuniform distribution of charges on atoms in the molecule. Though many authors state that low values of dipole moment [49] favour accumulation of the inhibitor molecule in the surface layer and therefore higher inhibition efficiency, the survey of literature $[50,51]$ reveals several irregularities in case of correlation of dipole moment with inhibitor efficiency. So, in general [52], there is no significant relationship between dipole moment values and inhibition efficiencies.

The global hardness $(\eta)$ and softness $(S)$ are important parameters which measure the reactivity and the molecular stability. A hard molecule has a large hardness value and vice versa [53]. In our study, the hardness of caffeine $(\eta=$ $2.570 \mathrm{eV}$ ) which can be considered as a low value [54] could explain the inhibiting properties of caffeine.

The number $(\Delta N)$ of electrons transferred is a parameter which indicates the tendency of a molecule to donate electrons. The higher the value of $\Delta N$, the greater the tendency of the molecule to donate electrons to the metal. In our case $(\Delta N=0.173)$, the positive sign shows that the molecule could donate electrons to the metal.

The electrophilicity index $(\omega)$ is another important parameter [55] which measures the propensity of chemical species to accept electrons; a high value of electrophilicity index describes a good electrophile while a small value of electrophilicity indicates a good nucleophile. In our study $\omega=2.234 \mathrm{eV}$ shows that caffeine has a good capacity to accept electrons from the metal.

The HOMO and LUMO orbital densities distributions are given in Figure 10.

In order to ascertain the role of individual atoms in the molecule, its local parameters including Mulliken charges $q_{N+1}, q_{N}$, and $q_{N-1}$, Fukui functions $f_{k}^{+}$and $f_{k}^{-}$, and local softness $s_{k}^{+}$and $s_{k}^{-}$were calculated. All these parameters are listed in Table 5.

The analysis of Table 5 shows that carbon C (10) is the probable site for nucleophilic attacks, whereas carbon $\mathbf{C}$ (14) is the probable site for electrophilic attacks. However, according to the literature [56], the local parameters $f_{k}^{+}, f_{k}^{-}$, $s_{k}^{+}$, and $s_{k}^{-}$are influenced by the basis sets. So, it is judicious to use relative indexes such as the relative nucleophilicity $\left(s_{k}^{+} / s_{k}^{-}\right)$ and the relative electrophilicity $\left(s_{k}^{-} / s_{k}^{+}\right)$. So, in our study $\mathbf{N}$ (7) which has the highest value of relative nucleophilicity index $s_{k}^{+} / s_{k}^{-}=7.240$ could be the probable nucleophilic attack site whereas $\mathbf{C}$ (2) with the highest value of relative electrophilicity $s_{k}^{-} / s_{k}^{+}=3.503$ could be the probable site of electrophilic attack.

Figure 10 allows verifying the belonging of each atom $k$ to the HOMO or LUMO densities regions in the molecule. From all these results, one can deduce (Figure 11) a pictorial presentation of forces acting between caffeine and aluminium surface.

At low temperatures, physical interactions exist between the protonated form of caffeine and chloride ions adsorbed on aluminium surface: physisorption is predominant. The rise in temperature leads to desorption of the protonated form of caffeine; only the neutral form, which is bonded to the metal, allows the inhibition of aluminium corrosion by chemisorption.

\section{Conclusion}

Caffeine was found to act as an effective corrosion inhibitor for aluminium in $1.0 \mathrm{M} \mathrm{HCl}$. The efficiency depends on the concentration and the temperature. The inhibition efficiency increases with increasing concentration of the inhibitor but decreases with rise in temperature. The adsorption of caffeine onto aluminium obeys the kinetic-thermodynamic adsorption isotherm of El-Awady. The negative sign of $\Delta G_{\text {ads }}^{0}$ suggests a spontaneous adsorption process. The values of 
TABLE 5: Local parameters of Caffeine.

\begin{tabular}{|c|c|c|c|c|c|c|c|c|c|}
\hline Atom & $q_{N+1}$ & $q_{N}$ & $q_{N-1}$ & $f_{k}^{+}$ & $f_{k}^{-}$ & $s_{k}^{+}$ & $s_{k}^{-}$ & $s_{k}^{+} / s_{k}^{-}$ & $s_{k}^{-} / s_{k}^{+}$ \\
\hline $1 \mathrm{C}$ & 0.4259 & 0.4753 & 0.5423 & -0.0494 & -0.0670 & -0.0192 & -0.0261 & 0.7370 & 1.3568 \\
\hline $2 \mathrm{C}$ & 0.1933 & 0.2179 & 0.3044 & -0.0247 & -0.0864 & -0.0096 & -0.0336 & 0.2855 & 3.5029 \\
\hline $3 \mathrm{C}$ & 0.5084 & 0.6324 & 0.6942 & -0.1240 & -0.0618 & -0.0482 & -0.0240 & 2.0059 & 0.4985 \\
\hline $4 \mathrm{C}$ & 0.7588 & 0.7852 & 0.8159 & -0.0264 & -0.0307 & -0.0103 & -0.0119 & 0.8595 & 1.1634 \\
\hline $5 \mathrm{C}$ & 0.0637 & 0.2199 & 0.2809 & -0.1562 & -0.0610 & -0.0608 & -0.0237 & 2.5623 & 0.3903 \\
\hline $6 \mathrm{H}$ & 0.0638 & 0.1695 & 0.2487 & -0.1058 & -0.0792 & -0.0411 & -0.0308 & 1.3351 & 0.7490 \\
\hline $7 N$ & -0.5530 & -0.5740 & -0.5772 & 0.0213 & 0.0029 & 0.0083 & 0.0011 & 7.2401 & 0.1381 \\
\hline $8 \mathrm{~N}$ & -0.5700 & -0.5900 & -0.5595 & 0.0198 & -0.0302 & 0.0077 & -0.0117 & -0.6565 & -1.5233 \\
\hline $9 \mathrm{~N}$ & -0.4880 & -0.4840 & -0.5009 & -0.0042 & 0.0168 & -0.0016 & 0.0065 & -0.2478 & -4.0357 \\
\hline $10 \mathrm{C}$ & -0.2910 & -0.3150 & -0.3382 & 0.0239 & 0.0235 & 0.0093 & 0.0091 & 1.0177 & 0.9826 \\
\hline $11 \mathrm{H}$ & 0.1754 & 0.1982 & 0.2316 & -0.0228 & -0.0335 & -0.0089 & -0.013 & 0.6820 & 1.4663 \\
\hline $12 \mathrm{H}$ & 0.1284 & 0.1773 & 0.2196 & -0.0489 & -0.0423 & -0.0190 & -0.0165 & 1.1562 & 0.8649 \\
\hline $13 \mathrm{H}$ & 0.1273 & 0.1772 & 0.2196 & -0.0499 & -0.0423 & -0.0194 & -0.0165 & 1.1787 & 0.8484 \\
\hline $14 \mathrm{C}$ & -0.3010 & -0.3220 & -0.3500 & 0.0208 & 0.0282 & 0.0081 & 0.0110 & 0.7355 & 1.3597 \\
\hline $15 \mathrm{H}$ & 0.1389 & 0.1977 & 0.2396 & -0.0588 & -0.0420 & -0.0229 & -0.0163 & 1.4000 & 0.7143 \\
\hline $16 \mathrm{H}$ & 0.1410 & 0.1816 & 0.2391 & -0.0407 & -0.0575 & -0.0158 & -0.0224 & 0.7072 & 1.4140 \\
\hline $17 \mathrm{H}$ & 0.1690 & 0.1816 & 0.2391 & -0.0126 & -0.0575 & -0.0049 & -0.0224 & 0.2187 & 4.5734 \\
\hline $18 \mathrm{C}$ & -0.2960 & -0.3150 & -0.3700 & 0.0195 & 0.0546 & 0.0076 & 0.0213 & 0.3568 & 2.8029 \\
\hline $19 \mathrm{H}$ & 0.1811 & 0.1990 & 0.2571 & -0.0179 & -0.0581 & -0.0070 & -0.0226 & 0.3081 & 3.2461 \\
\hline $20 \mathrm{H}$ & 0.1049 & 0.1991 & 0.2301 & -0.0942 & -0.0310 & -0.0366 & -0.0120 & 3.0417 & 0.3288 \\
\hline $21 \mathrm{H}$ & 0.1069 & 0.1662 & 0.2300 & -0.0593 & -0.0638 & -0.0231 & -0.0248 & 0.9297 & 1.0756 \\
\hline $22 \mathrm{O}$ & -0.6400 & -0.5400 & -0.4402 & -0.0994 & -0.1002 & -0.0387 & -0.0390 & 0.9928 & 1.0072 \\
\hline $23 \mathrm{O}$ & -0.5990 & -0.5270 & -0.4107 & -0.0728 & -0.1159 & -0.0283 & -0.0451 & 0.6276 & 1.5933 \\
\hline $24 \mathrm{~N}$ & -0.5490 & -0.5110 & -0.4456 & -0.0374 & -0.0657 & -0.0145 & -0.0256 & 0.5691 & 1.7573 \\
\hline
\end{tabular}

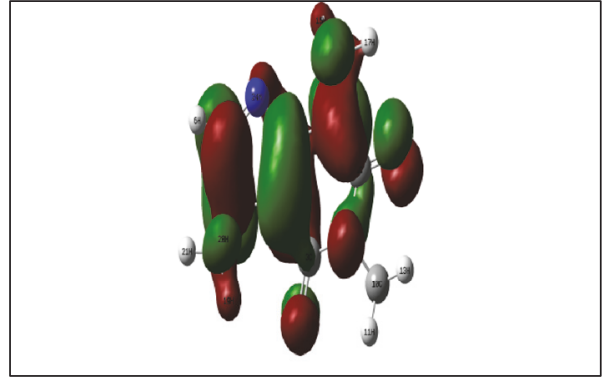

(a)

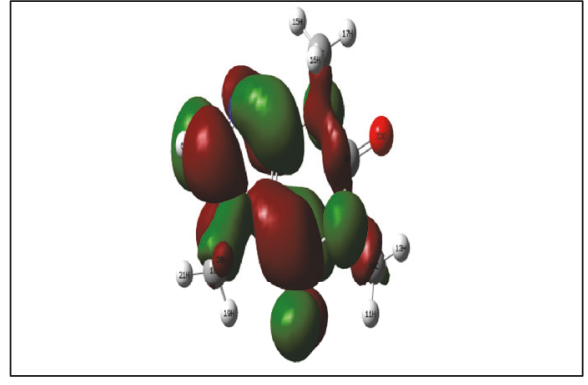

(b)

Figure 10: HOMO (a) and LUMO (b) densities of caffeine.

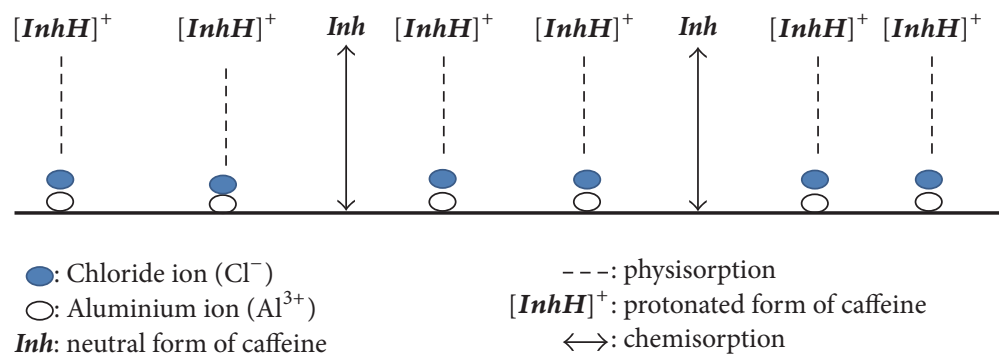

FIGURE 11: Schematic mechanism of aluminium corrosion inhibition in $1.0 \mathrm{M} \mathrm{HCl}$ by caffeine. 
change in adsorption free enthalpy $\Delta G_{\text {ads }}^{0}$ and that of the activation energy $E_{a}$ indicate the presence of both physisorption and chemisorption. The quantum chemical calculations are in good agreement with experimental results.

\section{Conflicts of Interest}

The authors declare that they have no conflicts of interest.

\section{References}

[1] A. S. Patel, V. A. Panchal, G. V. Mudaliar, and N. K. Shah, "Impedance spectroscopic study of corrosion inhibition of Al-Pure by organic Schiff base in hydrochloric acid," Journal of Saudi Chemical Society, vol. 17, no. 1, pp. 53-59, 2013.

[2] A. M. Abdel-Gaber, B. A. Abd-El-Nabey, I. M. Sidahmed, A. M. El-Zayady, and M. Saadawy, "Kinetics and thermodynamics of aluminium dissolution in $1.0 \mathrm{M}$ sulphuric acid containing chloride ions," Materials Chemistry and Physics, vol. 98, no. 2-3, pp. 291-297, 2006.

[3] S. Berrada, M. Elboujdaini, and E. Ghali, "Comportement electrochimique des alliages d'aluminium 2024 ET 7075 dans un milieu salin," Journal of Applied Electrochemistry, vol. 22, no. 11, pp. 1065-1071, 1992.

[4] Z. Szklarska-Smialowska, "Insight into the pitting corrosion behavior of aluminum alloys," Corrosion Science, vol. 33, no. 8, pp. 1193-1202, 1992.

[5] R. Ambat and E. S. Dwarakadasa, "Studies on the influence of chloride ion and $\mathrm{pH}$ on the electrochemical behaviour of aluminium alloys 8090 and 2014," Journal of Applied Electrochemistry, vol. 24, no. 9, pp. 911-916, 1994.

[6] A. Yurt, S. Ulutas, and H. Dal, "Electrochemical and theoretical investigation on the corrosion of aluminium in acidic solution containing some Schiff bases," Applied Surface Science, vol. 253, no. 2, pp. 919-925, 2006.

[7] N. A. Negm, N. G. Kandile, E. A. Badr, and M. A. Mohammed, "Gravimetric and electrochemical evaluation of environmentally friendly nonionic corrosion inhibitors for carbon steel in 1M HCl," Corrosion Science, vol. 65, pp. 94-103, 2012.

[8] P. Bommersbach, C. Alemany-Dumont, J. P. Millet, and B. Normand, "Formation and behaviour study of an environmentfriendly corrosion inhibitor by electrochemical methods," Electrochimica Acta, vol. 51, no. 6, pp. 1076-1084, 2005.

[9] X. Li, S. Deng, and H. Fu, "Inhibition by tetradecylpyridinium bromide of the corrosion of aluminium in hydrochloric acid solution," Corrosion Science, vol. 53, no. 4, pp. 1529-1536, 2011.

[10] S. Şafak, B. Duran, A. Yurt, and G. Türkoĝlu, "Schiff bases as corrosion inhibitor for aluminium in $\mathrm{HCl}$ solution," Corrosion Science, vol. 54, no. 1, pp. 251-259, 2012.

[11] R. T. Loto, C. A. Loto, and A. P. I. Popoola, "Corrosion inhibition of thiourea and thiadiazole derivatives: a review," Journal of Materials and Environmental Science, vol. 3, no. 5, pp. 885-894, 2012.

[12] A. S. Fouda, K. Shalabi, and N. H. Mohamed, "Corrosion inhibition of Aluminium in Hydrochloric Acid Solutions using some chalcone derivatives," International Journal of Innovative Research in Science Engineering and Technology, vol. 3, no. 3, pp. 9861-9875, 2014.
[13] O. N. Eddy, B. I. Ita, N. E. Ibissi, and E. E. Ebenso, "Experimental and quantum studies on the corrosion inhibition potentials of 2(2-oxo indolin-3-Ylideneamino) Acetic Acid and indoline-2,3Dione," International Journal of Electrochemical Science, vol. 6, pp. 1027-1044, 2011.

[14] X. Li, S. Deng, and X. Xie, "Experimental and theoretical study on corrosion inhibition of oxime compounds for aluminium in $\mathrm{HCl}$ solution," Corrosion Science, vol. 81, pp. 162-175, 2014.

[15] I. B. Obot and N. O. Obi-Egbedi, "Fluconazole as an inhibitor for aluminium corrosion in $0.1 \mathrm{M} \mathrm{HCl,"} \mathrm{Colloids} \mathrm{and} \mathrm{Surfaces}$ A: Physicochemical and Engineering Aspects, vol. 330, no. 2-3, pp. 207-212, 2008.

[16] I. A. Adejoro, C. U. Ibeji, and D. C. Akintayo, "Quantum Descriptors and Corrosion Inhibition Potentials of Amodaquine and Nivaquine," Chemical Sciences Journal, vol. 08, no. 01, 2017.

[17] A. A. Khadom, A. S. Yaro, and A. A. H. Kadum, "Corrosion inhibition by naphthylamine and phenylenediamine for the corrosion of copper-nickel alloy in hydrochloric acid," Journal of the Taiwan Institute of Chemical Engineers, vol. 41, no. 1, pp. 122-125, 2010.

[18] A. Y. Musa, A. A. Khadom, A. A. H. Kadhum, A. B. Mohamad, and M. S. Takriff, "Kinetic behavior of mild steel corrosion inhibition by 4-amino-5-phenyl-4H-1,2,4-trizole-3-thiol," Journal of the Taiwan Institute of Chemical Engineers, vol. 41, no. 1, pp. 126-128, 2010.

[19] A. Rahim and J. Kassim, "Recent Development of Vegetal Tannins in Corrosion Protection of Iron and Steel," Recent Patents on Materials Sciencee, vol. 1, no. 3, pp. 223-231, 2008.

[20] C. Lee, W. Yang, and R. G. Parr, "Development of the ColleSalvetti correlation-energy formula into a functional of the electron density," Physical Review B: Condensed Matter and Materials Physics, vol. 37, no. 2, pp. 785-789, 1988.

[21] M. J. Frisch, G. W. Trucks, H. B. Schlegel et al., Gaussian03, Gaussian, Inc., Pittsburgh, Penn, USA, 2003.

[22] R. G. Parr and W. Yang, Density Functional Theory of Atoms and Molecules, Oxford University Press, Oxford, UK, 1989.

[23] R. G. Parr, R. A. Donnelly, M. Levy, and W. E. Palke, "Electronegativity: the density functional viewpoint," The Journal of Chemical Physics, vol. 68, no. 8, pp. 3801-3807, 1977.

[24] R. G. Parr and R. G. Pearson, "Absolute hardness: companion parameter to absolute electronegativity," Journal of the American Chemical Society, vol. 105, no. 26, pp. 7512-7516, 1983.

[25] T. Koopmans, "Über die Zuordnung von Wellenfunktionen und Eigenwerten zu den Einzelnen Elektronen Eines Atoms," Physica A: Statistical Mechanics and its Applications, vol. 1, no. 1-6, pp. 104-113, 1934.

[26] R. G. Pearson, "Hard and soft acids and bases-the evolution of a chemical concept," Coordination Chemistry Reviews, vol. 100, no. C, pp. 403-425, 1990.

[27] A. Kokalj and N. Kovačević, "On the consistent use of electrophilicity index and HSAB-based electron transfer and its associated change of energy parameters," Chemical Physics Letters, vol. 507, no. 1-3, pp. 181-184, 2011.

[28] R. G. Parr, L. V. Szentpály, and S. Liu, "Electrophilicity index," Journal of the American Chemical Society, vol. 121, no. 9, pp. 1922-1924, 1999.

[29] K. Fukui, "Role of frontier orbitals in chemical reactions," Science, vol. 218, no. 4574, pp. 747-754, 1982.

[30] W. Yang and W. J. Mortier, "The use of global and local molecular parameters for the analysis of the gas-phase basicity of amines," Journal of the American Chemical Society, vol. 108, no. 19 , pp. 5708-5711, 1986. 
[31] W. Yang and R. G. Parr, "Hardness, Softness and the Fukui function in the electronic theory of metals and catalysis," Proceedings of the National Academy of Sciences, vol. 82, no. 20, pp. 67236726, 1985.

[32] I. B. Obot, S. A. Umoren, and N. O. Obi-Egbedi, "Corrosion inhibition and adsorption behaviour for aluminium by extract of Amingeria robusta in $\mathrm{HCl}$ solution: synergistic effect of Iodide ions," Journal of Materials and Environmental Science, vol. 2, no. 1, pp. 60-71, 2011.

[33] K. M. Manamela, L. C. Murulana, M. M. Kabanda, and E. E. Ebenso, "Adsorptive and DFT studies of some imidazolium based ionic liquids as corrosion inhibitors for zinc in acidic medium," International Journal of Electrochemical Science, vol. 9, no. 6, pp. 3029-3046, 2014.

[34] F. Bentiss, M. Lebrini, and M. Lagrenée, "Thermodynamic characterization of metal dissolution and inhibitor adsorption processes in mild steel/2,5-bis(n-thienyl)-1,3,4-thiadiazoles/ hydrochloric acid system," Corrosion Science, vol. 47, no. 12, pp. 2915-2931, 2005.

[35] H. Ashassi-Sorkhabi, B. Shabani, B. Aligholipour, and D. Seifzadeh, "The effect of some Schiff bases on the corrosion of aluminum in hydrochloric acid solution," Applied Surface Science, vol. 252, no. 12, pp. 4039-4047, 2006.

[36] R. F. V. Villamil, P. Corio, S. M. L. Agostinho, and J. C. Rubim, "Effect of sodium dodecylsulfate on copper corrosion in sulfuric acid media in the absence and presence of benzotriazole," Journal of Electroanalytical Chemistry, vol. 472, no. 2, pp. 112119, 1999.

[37] G. Moretti, F. Guidi, and G. Grion, “Tryptamine as a green iron corrosion inhibitor in $0.5 \mathrm{M}$ deaerated sulphuric acid," Corrosion Science, vol. 46, no. 2, pp. 387-403, 2004.

[38] A. K. Singh and M. A. Quraishi, "Effect of Cefazolin on the corrosion of mild steel in $\mathrm{HCl}$ solution," Corrosion Science, vol. 52, no. 1, pp. 152-160, 2010.

[39] E. A. Noor, "Potential of aqueous extract of Hibiscus sabdariffa leaves for inhibiting the corrosion of aluminum in alkaline solutions," Journal of Applied Electrochemistry, vol. 39, no. 9, pp. 1465-1475, 2009.

[40] S. A. Umoren, I. B. Obot, I. E. Apkabio, and S. E. Etuk, "Adsorption and Corrosion inhibitive properties of Vigna unguiculata in alkaline acidic media," Pigment \& Resin Technology, vol. 37, pp. 98-105, 2000.

[41] I. A. Adejoro, D. C. Akintayo, and C. U. Ibeji, “The Efficiency of Chloroquine as Corrosion Inhibitor for Aluminium in $1 \mathrm{M}$ $\mathrm{HCl}$ Solution : Experimental and DFT Study," Jordan Journal of Chemistry, vol. 11, no. 1, pp. 38-49, 2016.

[42] A. Y. Musa, A. A. H. Kadhum, A. B. Mohamad, A. A. B. Rahoma, and H. Mesmari, "Electrochemical and quantum chemical calculations on 4,4-dimethyloxazolidine-2-thione as inhibitor for mild steel corrosion in hydrochloric acid," Journal of Molecular Structure, vol. 969, no. 1-3, pp. 233-237, 2010.

[43] H. Ashassi-Sorkhabi, B. Shaabani, and D. Seifzadeh, "Corrosion inhibition of mild steel by some schiff base compounds in hydrochloric acid," Applied Surface Science, vol. 239, no. 2, pp. 154-164, 2005.

[44] N. O. Eddy, H. Momoh-Yahaya, and E. E. Oguzie, “Theoretical and experimental studies on the corrosion inhibition potentials of some purines for aluminum in $0.1 \mathrm{M} \mathrm{HCl}$," Journal of Advanced Research, vol. 6, no. 2, pp. 203-217, 2015.

[45] Y. Yan, W. Li, L. Cai, and B. Hou, "Electrochemical and quantum chemical study of purines as corrosion inhibitors for mild steel in $1 \mathrm{M} \mathrm{HCl}$ solution," Electrochimica Acta, vol. 53, no. 20, pp. 5953-5960, 2008.

[46] I. B. Obot and N. O. Obi-Egbedi, "Inhibitory effect and adsorption characteristics of 2,3-diaminonaphthalene at aluminum/ hydrochloric acid interface: Experimental and theoretical study," Surface Review and Letters, vol. 15, no. 6, pp. 903-910, 2008.

[47] A. Döner, R. Solmaz, M. Özcan, and G. Kardaş, "Experimental and theoretical studies of thiazoles as corrosion inhibitors for mild steel in sulphuric acid solution," Corrosion Science, vol. 53, no. 9, pp. 2902-2913, 2011.

[48] Y. Qiang, S. Zhang, L. Guo, X. Zheng, B. Xiang, and S. Chen, "Experimental and theoretical studies of four allyl imidazolium-based ionic liquids as green inhibitors for copper corrosion in sulfuric acid," Corrosion Science, vol. 119, pp. 6878, 2017.

[49] N. Khalil, "Quantum chemical approach of corrosion inhibition," Electrochimica Acta, vol. 48, no. 18, pp. 2635-2640, 2003.

[50] K. F. Khaled, K. Babić-Samardžija, and N. Hackerman, "Theoretical study of the structural effects of polymethylene amines on corrosion inhibition of iron in acid solutions," Electrochimica Acta, vol. 50, no. 12, pp. 2515-2520, 2005.

[51] G. Bereket, E. Hür, and C. Öğretir, "Quantum chemical studies on some imidazole derivatives as corrosion inhibitors for iron in acidic medium," Journal of Molecular Structure, vol. 578, no. $1-3$, pp. 79-88, 2002.

[52] G. Gece, "The use of quantum chemical methods in corrosion inhibitor studies," Corrosion Science, vol. 50, no. 11, pp. 29812992, 2008.

[53] N. O. Obi-Egbedi, I. B. Obot, M. I. El-Khaiary, S. A. Umoren, and E. E. Ebenso, "Computational simulation and statistical analysis on the relationship between corrosion inhibition efficiency and molecular structure of some phenanthroline derivatives on mild steel surface," International Journal of Electrochemical Science, vol. 6, no. 11, pp. 5649-5675, 2011.

[54] M. A. Bedair, "The effect of structure parameters on the corrosion inhibition effect of some heterocyclic nitrogen organic compounds," Journal of Molecular Liquids, vol. 219, pp. 128-141, 2016.

[55] J. Saranya, P. Sounthari, K. Parameswari, and S. Chitra, "Adsorption and density functional theory on corrosion of mild steel by a quinoxaline derivative," Der Pharma Chemica, vol. 7, no. 8, pp. 187-196, 2015.

[56] T. Arslan, F. Kandemirli, E. E. Ebenso, I. Love, and H. Alemu, "Quantum chemical studies on the corrosion inhibition of some sulphonamides on mild steel in acidic medium," Corrosion Science, vol. 51, no. 1, pp. 35-47, 2009. 

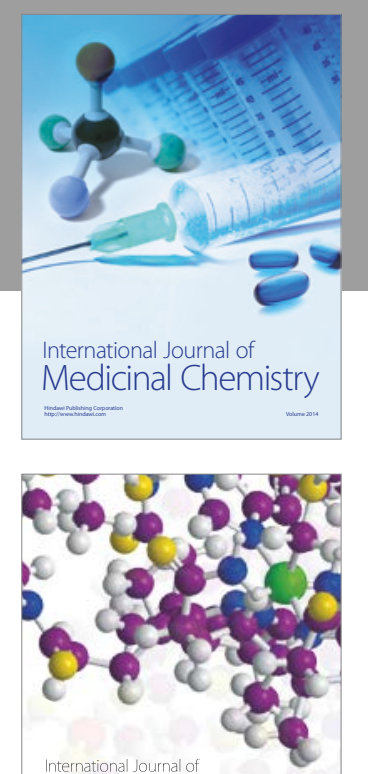

Carbohydrate Chemistry

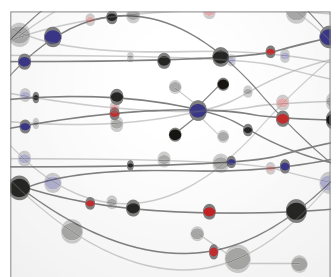

The Scientific World Journal
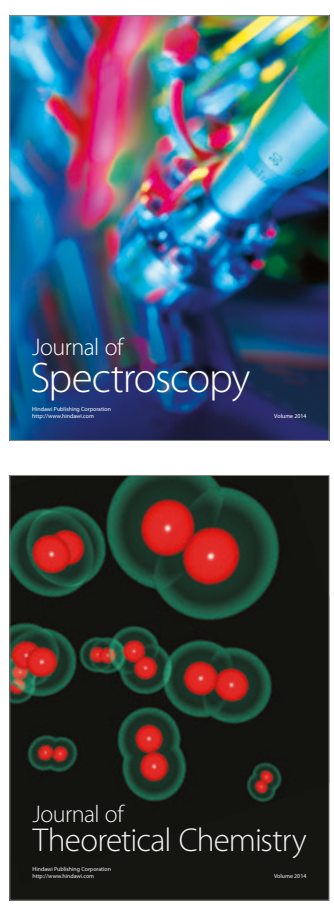
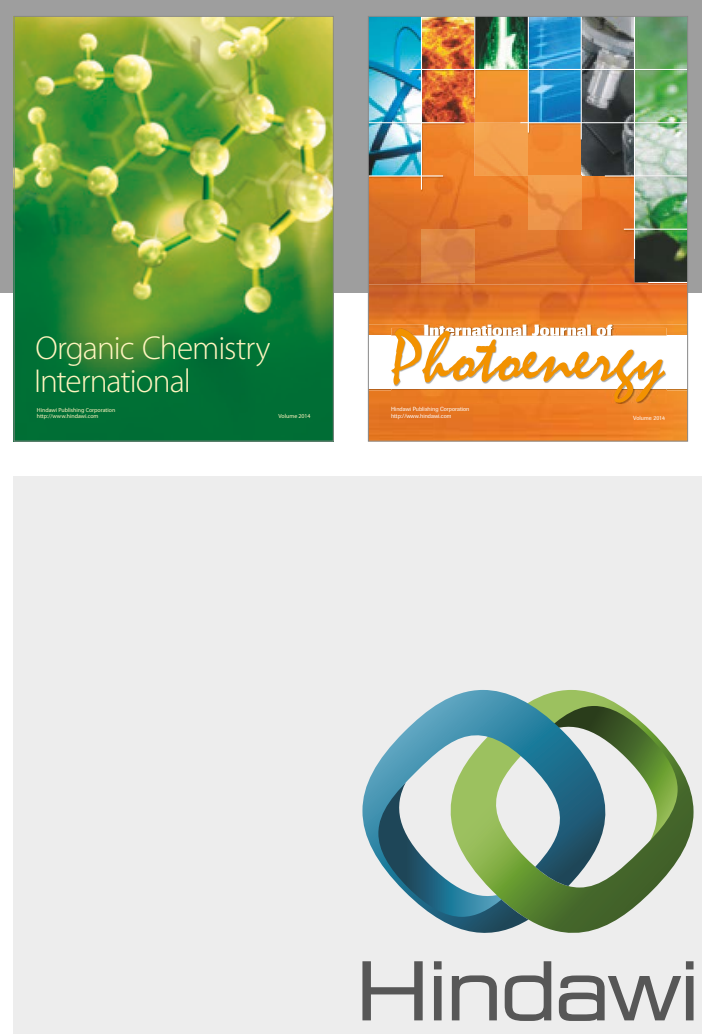

Submit your manuscripts at

https://www.hindawi.com

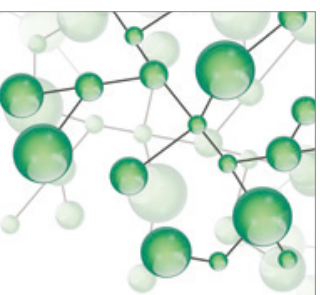

International Journal of

Inorganic Chemistry

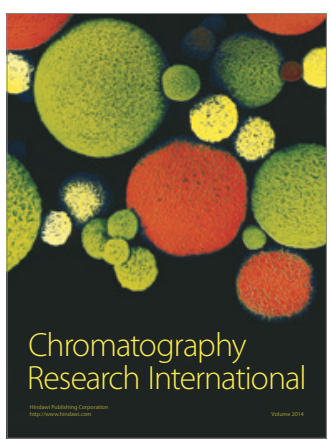

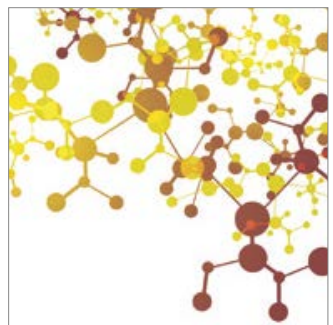

Applied Chemistry
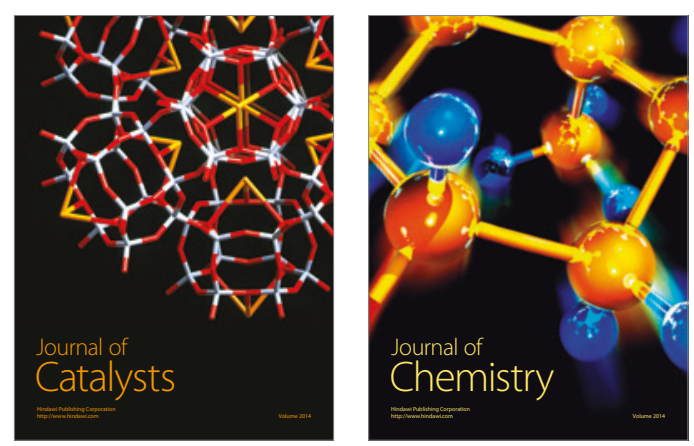
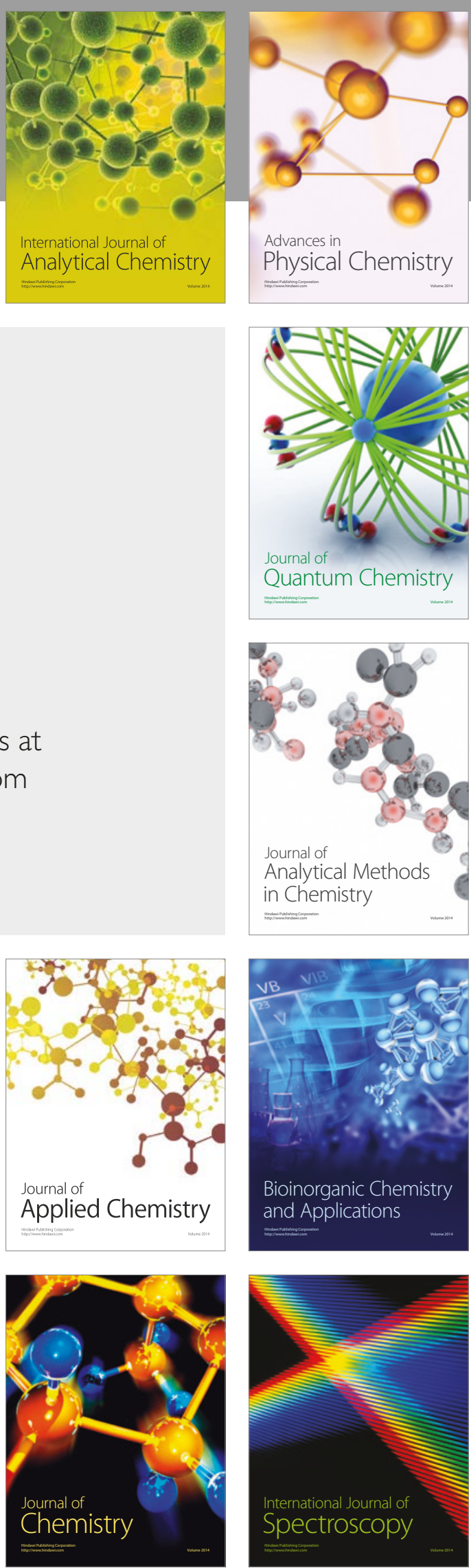